\title{
On the Reform of Integrated Planning Art Management Mode
}

\author{
Lin Lin \\ College of the Arts, Taishan University, Taian Shandong, 271000, China \\ Hansei University, Gunpo-si, Gyeonggi-do, 435742, Korea
}

Keywords: integration; planning; art management mode; reform

\begin{abstract}
Along with the advancement of marketization accelerating, the flexibility of the art cause plays an increasingly important role in its development process, integrated planning art management mode no longer meets the needs of the times. Under this background, therefore, the call for the reform of art management mode is more and more strong. The integrated planning art management mode not only makes innovative thinking of people in the art field continuously rigid, but also makes the art cause confined to the shell of planning mode for a long time, unable to play its real function. Therefore, it is imperative to reform the current integrated planning art management mode. Based on the author's many years of experience, this paper elaborates the theoretical origin and existing problems of China's current integrated planning art management mode and proposes reforming measures. It is hoped to be beneficial to the reform of art management mode of our country.
\end{abstract}

\section{The Background of Integrated Planning Art Management Mode}

\subsection{Specific political and economic background}

The forming period of integrated planning art management mode was mainly before the Cultural Revolution. The unprecedented prosperity of literature and art in this period has led to the activity of reform and abolishment of old thought to be carried out closely, thus forming a specific art management mode. Therefore, under that background, the integrated planning art management mode was actually conducive to the development of art cause at that time. After the founding of new China, many things waiting to be done, the backward economic and technological conditions have greatly restricted the development of the art field. The social background at that time could not bring the resources needed for the flexible development of art field. In addition, the political background after the founding of new China also led to the rapid rise of planned economy in our country, which affected the management mode of the art field.

\subsection{Comprehensive study the Soviet art management mode}

Since the early days of the founding of new China, China has reached a friendly alliance with the Soviet Union. Therefore, the art management mode of our country in this period was mainly inspired by the Soviet management mode. During this period, the Soviet Union fully implemented the strategy of planned economy and made an uniform management of the art cause, so as to promote the preservation and development of the art field in its general background. On the basis of deeply considering its development mode and the political and economic situation in our country, China introduced it, adding the current art management mode of our country, which has formed the integrated planning art management mode. In addition, the characteristics of communism also made China regard art as the key of integrated planning development at the beginning of its development. Therefore, it can be said that the rise of China's integrated planning art management mode is affected to some extent by the Soviet Union's management mode.

\subsection{To inherit the art management mode of liberated areas}

The rise of China's integrated planning art management mode was also influenced by the art management mode of the liberated areas at that time. According to investigation, all the artistic undertakings in the liberated areas of our country during the liberation period were under the war, and 
all the people engaged in the liberation cause were also soldiers. This background made the art management mode in the liberation area essentially consistent with the military management mode, therefore, the cause of the art must be under the unified management of the army. In the long run, an integrated planning art management mode has been formed. In addition, the internal situation of the liberated areas also makes the flexible development of the art industry an extravagant hope. The long-term strict militarization management makes the integrated planned art management mode emerge quietly. In addition, the internal situation of the liberated areas also made the flexible development of the art cause to be an extravagant hope. The long-term strict militarization management made the integrated planning art management mode emerge quietly.

\section{The Current Situation of China's Integrated Planning Art Management Mode}

\subsection{Limiting the innovative development of the art field}

Specific art management mode is necessarily restricted to specific political and economic development situation, so as the change of political and economic situation, the integrated planned art management mode can no longer adapt to the current art development situation of our country. On the one hand, the integrated planned art management mode makes the internal contents in the art field can not be innovated for a long time. Under the background of unified management, it must not give full play to its advantages, which is not conducive to the long-term high-quality development of the art field. On the other hand, the integrated planning art management mode makes the art cause in different regions present a homogenous development trend, and fails to truly reflect the strengths and weaknesses of different regions. Therefore, in order to achieve great development of China's art cause, we must adhere to the diversified development path, adding regional features to the overall development, constantly strengthen the innovative art and innovative thinking, thereby, China's art management will be quality developed by the continuous innovation.

\subsection{Hindering the development of art marketization}

With the constant acceleration of marketization process, the marketization of the art field has become the current development trend of art management mode of our country. However, the long-term serious integrated planning management mode makes the art field confined to the fixed thinking formed for a long time, which makes it in a difficult position on the road of market development and unable to be separated from the thinking of planned development, the rapid development of art field is bound to be hindered in the long run. In addition, the integrated planned art management mode has formed its inherent development path for a long time, the intervention of marketization will make the art field unable to distinguish its own positioning, which leads to the confusion in character setting. Therefore, the long-term serious integrated planning art development mode has hindered the development of marketization in the art field.

\subsection{Causing the rigid management mode in the art field}

The integrated planning art management mode not only makes it easy to confuse the role cognition in the art field, but also makes the art management mode gradually rigid. In case of the management system, the government and enterprises are not divided, the control and management rights are concentrated in the same person. As a result, there is no need for innovative development in the field of art, which hinders the scientific and standardized development of art management mode. In addition, the long-term integrated planning management mode within the art field makes it impossible for the real economy engaged in art management to enjoy real rights. Power is often concentrated in administrative departments, which do not have the ability to thoroughly observe the market and appreciate the arts. As a result, the art field has suffered many obstacles in its development process, which is not conducive to the development and innovation of the art field in the long run. 


\section{The Challenge of Integrated Planning Art Management Mode}

\subsection{The acceleration of marketization}

As mentioned above, the most important thing for art field to truly realize its own development is to promote continuous innovation and break the original ideological shackles, broaden the boundaries of the art field and get rid of the old ideas. In the process of innovative development in the art field, the biggest influence is the continuous development of marketization. Therefore, the current integrated planning art management mode is facing a serious shock of marketization. Since the reform and opening, the marketization process of development in various fields has been accelerating, the integrated planning art management mode is no longer suitable for the current marketization process in China. Therefore, the acceleration of marketization process seriously challenges the current integrated planning art management mode in our country.

\subsection{The current political and economic development}

The current political and economic status has made the integrated planning art management mode no longer adapt to the current political and economic development mode in China. First of all, the multi-level and wide-field management mode in political field has caused the art management mode to be ignored to a certain extent in political field. The political field can only define the specific management mode of art in the general policy, and cannot involve the deeper level. The marketization management mode at the economic level also makes the current art management mode have certain defects. Therefore, it is imperative to carry out a proper reform of integrated planning art management mode.

\section{The Reform Direction and Measures of Art Management Mode}

\subsection{The overall direction of art development at the macro level}

As mentioned above, the current integrated planning art management mode has not adapted to the new situation of China in both political and economic fields. Therefore, it is imperative to reform the current art management mode. In the process of reform, it can be carried out from the macro, medium and micro levels. At the macro level, the state can define the current art management mode as a whole, so as to determine the general direction of the art development. The government can manage it by means of legislation, supervision and so on. First, the state and government must formulate strict management systems and legal norms, formulate the summary of specific art management modes and development trends, on this basis, to complete the overall reform of current art management mode, to promote the development of art management mode to be more scientific and marketization.

\subsection{At the medium level, flexible art management mode should be set up within the art industry}

At the medium level, we must start from within the internal of art industry to develop the current art management mode. Through strict political, economic and cultural measures to ensure the flexible development of art industry in China. First of all, from the political level, the art industry can set up strict rules and regulations to achieve the purpose of the integrated reform of art industry by monitoring the behavior of people in art industry. The art industry can also encourage the overall innovative consciousness and thinking by giving appropriate incentives to specific artistic creation, encouraging the behavior of artistic adaptation and creation of art practitioners, so as to encourage innovation of art practitioners. From the economic perspective, the art industry can provide appropriate financial assistance to the creative behaviors of art practitioners and encourage their innovative awareness. In addition, the art industry can motivate the change of the management mode of art industry through macro-economic control to promote the reform of the overall mode of the art industry. In terms of culture, the development of the art industry requires in-depth exploration of the local cultural connotation. On the basis of integrated development, encouraging regional innovation and adding regional characteristics can make the management mode of art field changed qualitatively and promote the reform of current art management mode in China. 


\subsection{At the micro level, artists are encouraged to start their own businesses}

As mentioned above, one of the major problems existing in integrated planning art management mode is that it has no distinction between government and enterprises. Its specific management organization has not been clearly distinguished, which makes the current art field in China in a serious state of chaos at management level. In the long run, this will inevitably lead to the art management mode rigid, which is not conducive to the long-term development of art field. Therefore, to change this situation, we can start from the separation of government functions from enterprise management in the management mode of art industry. On the one hand, to promote the marketization and enterprization in the field of art in our country, make it able to sensitively response to the demand of the market, so as to develop under the demand of the market and can be more in line with the development trend of China's marketization. On the other hand, to realize the separation of government functions from enterprise management in art management mode can also encourage artists to start their own businesses. Based on its own advantages and characteristics, it will start its own business independently, so as to realize its own market development in the process of operation and promote the reform and development of China's integrated art management mode. To start the business independently based on the advantages and characteristics, so as to realize the development of marketization in the process of operation and promote the reform and development of integrated art management mode in China.

\section{Conclusion}

China's integrated planning art management mode originated from the early days of the founding of new China, which is closely related to the specific political and economic development status in China. It has experienced the shock of marketization development trend during its development process, it has no longer been adapted to the current situation of development of China and the overall development trend of the world so far. Therefore, it is necessary to reform the integrated planning art management mode to promote the scientific development of art management mode in China. In order to reform the current art management mode, it is necessary to take appropriate measures. Combined with the author's many years of research experience, this paper elaborates from macro, meso and micro three levels, hoping to contribute to the reform of the art management mode in China.

\section{References}

[1] Jun Wang. A preliminary study on the reform of integrated planning art management mode, Sichuan Opera, 1989(02):41-43.

[2] Yinggang Gao. The cultivation model of art management talents in European and American countries and its reference significance to contemporary China, Hundred Schools in Arts, 2012, 28(03):82-87.

[3] Qiaoming Cheng. Research on the five-level management model of art management, Journal of Changchun University of Science and Technology (social science edition), 2012, 25(09): 130-132.

[4] Deling Wang. Study on the innovation of art management and its management model, Chinese foreign investment, 2012(24):154+156.

[5] Yunfeng He. Several thinking about the teaching of art management major (Two) to see the adjustment and update of teaching mode and idea from four teaching plans of art management professional of Central Conservatory of Music, Chinese music, 2011 (01) : 117-127. 